\title{
The Uptake and Use of Telemonitoring in Chronic Care Between 2014 and 2019: Nationwide Survey Among Patients and Health Care Professionals in the Netherlands
}

Martine W J Huygens ${ }^{1}$, MSc, PhD; Helene R Voogdt-Pruis ${ }^{2}$, MSc, PhD; Myrah Wouters ${ }^{3}$, MA; Maaike M Meurs ${ }^{1}$, MSc, PhD; Britt van Lettow ${ }^{4}, \mathrm{MSc}, \mathrm{PhD}$; Conchita Kleijweg ${ }^{4}$, MSc; Roland D Friele ${ }^{1}, \mathrm{MSc}, \mathrm{PhD}$

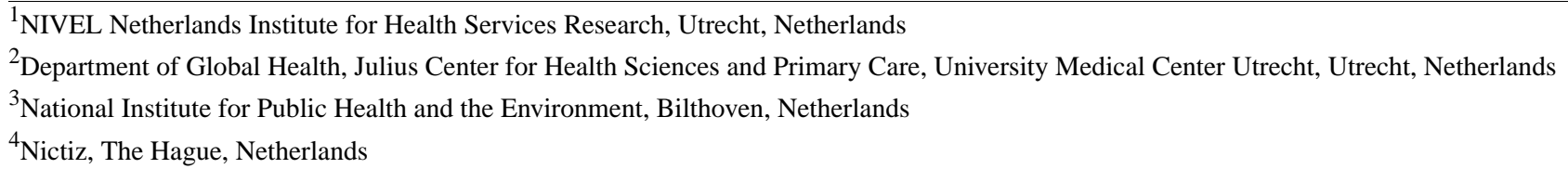

\section{Corresponding Author:}

Helene R Voogdt-Pruis, MSc, $\mathrm{PhD}$

Department of Global Health

Julius Center for Health Sciences and Primary Care

University Medical Center Utrecht

PO Box 85500

Utrecht, 3508 GA

Netherlands

Phone: 310651964815

Email: h.r.pruis@umcutrecht.nl

\section{Abstract}

Background: Telemonitoring could offer solutions to the mounting challenges for health care and could improve patient self-management. Studies have addressed the benefits and challenges of telemonitoring for certain patient groups.

Objective: This paper will examine the nationwide uptake of telemonitoring in chronic care in the Netherlands from 2014 to 2019 by means of an annual representative survey among patients and health care professionals.

Methods: Between 2014 and 2019, approximately 2900 patients with chronic diseases, 700 nurses, and 500 general practitioners (GPs) and medical specialists received a questionnaire. About 30 questions addressed topics about the use of eHealth and experiences with it, including data about telemonitoring.

Results: Between 2014 and 2019, the use of telemonitoring remained stable for all groups except medical specialists. In medical specialist departments, the use of telemonitoring increased from $11.2 \%(18 / 161)$ in 2014 to $19.6 \%(36 / 184)$ in $2019\left(\chi_{4}^{2}=12.3\right.$; $P=.02)$. In 2019 , telemonitoring was used by $5.8 \%$ (28/485) of people with chronic disease. This was $18.2 \%(41 / 225)$ in GP organizations and 40.4\% (44/109), 38.0\% (78/205), and 8.9\% (29/325) in the organizations of nurses working in primary, secondary, and elderly care, respectively. Up to $10 \%$ of the targeted patient group such as diabetics were regarded by health care professionals as suitable for using telemonitoring. The main benefits mentioned by the patients were "comfort" (421/1043, 40.4\%) and "living at home for longer/more comfortably" (334/1047, 31.9\%). Health care professionals added "improvement of self-management" $(63 / 176,35.8 \%$ to $57 / 71,80.3 \%)$, "better understanding of the patient's condition" $(47 / 176,26.7 \%$ to $42 / 71$, $59.2 \%)$, "reduction of workload" (53/134, 39.6\% of nurses in elderly care), "better tailoring of care plan to the patient's situation" (95/225, 42.2\% of GPs), and "saves time for patients/caregivers" (61/176, 34.7\% of medical specialists). Disadvantages mentioned by professionals were that "it takes time to monitor data" $(13 / 130,10 \%$ to $108 / 225,48.0 \%)$, "it takes time to follow up alerts" $(15 / 130,11.5 \%$ to $117 / 225,52.0 \%)$, and "it is difficult to estimate which patients can work with telemonitoring" (22/113, $19.5 \%$ to $94 / 225,41.8 \%$ ).

Conclusions: The uptake of telemonitoring in Dutch chronic care remained stable during 2014-2019 but increased among medical specialists. According to both patients and professionals, telemonitoring improves the quality of life and quality of care. Skills for suitably including eligible patients and for allocating the tasks of data monitoring and follow-up care within the team would help to further increase the use of telemonitoring. 
(J Med Internet Res 2021;23(5):e24908) doi: 10.2196/24908

\section{KEYWORDS}

eHealth; telemonitoring; self-management; telemedicine; telehealth

\section{Introduction}

\section{Added Value of Telemonitoring}

Telemonitoring could broaden access to health care and offer solutions to the mounting challenges for the health care system such as an ageing population, which is creating a demand for long-term care, rising expectations from patients who are better informed about health issues, and the pressure on national health care budgets due to these demands [1-4]. Telemonitoring uses technology such as videoconferencing, email, remote electronic monitoring equipment, social network apps, and internet portals to allow monitoring and self-monitoring of health data by patients and health-related education and long-distance interventions by health care professionals (HCPs) [5-7]. Several studies have addressed the benefits of telemonitoring, for example, better access to health care and the cost-effective delivery of health care. Telemonitoring could reduce face-to-face consultations and clinic visits. In addition, telemonitoring improves the quality of care and clinical outcomes through continuous and reliable monitoring of data, immediate assessment, triage, and interventions. Telemonitoring could also improve patient empowerment, self-management, and compliance [4,8-16].

\section{Implementation of Telemonitoring}

Implementation and actual use of telemonitoring in daily practice require well-thought-out action plans, for example, for selecting appropriate interventions or for tailoring the design to the needs of the user group. In addition, telemonitoring should be seamlessly integrated into the health care processes and should avoid disrupting the HCPs' existing workflow. It was also recommended that telemonitoring should be part of "blended care" as both patients and HCPs prefer face-to-face encounters $[17,18]$. Implementation programs for telemonitoring should tackle barriers to actual use. Some studies found barriers that are related to "users" of telemonitoring such as lack of digital skills, resistance to change, and lack of direct personal benefit. Mentioned examples of barriers that were related to the context were lack of privacy (or fear of it), security, patient safety, a properly working internet connection, proper technological infrastructure, regulations, funding, and task allocation $[4,19]$.

\section{Telemonitoring in the Netherlands}

In the Netherlands, an enabling factor related to the context of telemonitoring is the availability of $4 \mathrm{G}$ mobile networks and high-speed broadband Internet access, even in rural areas [20]. Currently, $90 \%$ of Dutch people use the internet daily. In particular, over the last 5 years, older people, the less well-educated, those born outside the country, and low-income households have caught up [21]. In terms of policy, several national documents, studies, and guidelines for eHealth have been developed during the last 10 years addressing privacy and patient safety in the use of eHealth [22,23]. In 2012, the Dutch
National Implementation Agenda for eHealth was launched, followed by the eHealth Governance Covenant 2014 - 2019 [24] and a framework on the use of eHealth by HCPs [23]. As regards funding, telemonitoring is covered by the Dutch health insurance system; in particular, the funding of follow-up consultations improved in 2019. Still, HCPs do not have the funds to upscale telemonitoring [25].

\section{Annual Nationwide Representative Study Among Health Care Professionals}

Since 2013, the nationwide uptake of eHealth in general by patients and HCPs has been investigated annually and reported in what is known as the "eHealth-monitor." This investigation was commissioned by the Dutch Ministry of Health, Welfare and Sport. The aim of the annual eHealth-monitor was to investigate the implementation of eHealth and to boost its implementation in subsequent health care policy. Every year, about 30 questions addressed topics on the use of eHealth and experiences with it, including telemonitoring. The findings from the perspectives of nurses, general practitioners (GPs), medical specialists, and patients with a chronic disease increased the understanding of the implementation of telemonitoring and the uptake of telemonitoring in daily practice. To our knowledge, our study is the first scientific paper on the nationwide uptake of telemonitoring for all patient groups in chronic care over a long period of time. We analyzed data on the actual use of telemonitoring by patients and HCPs in daily chronic care. In addition, opinions on and experiences with telemonitoring were analyzed.

\section{Methods}

\section{Study Design}

Since 2013, data for the eHealth-monitor has been collected annually using various nationwide panels. Written and online questionnaires on eHealth were sent to GPs, medical specialists, nurses (practice nurses and practice assistants working in elderly care, GP care, and hospital care), and people with chronic diseases. All participants were approached in March. Nonresponders initially received 1 written or 2 online reminders. For this study, data from respondents on questions about telemonitoring between 2014 and 2019 were used.

\section{Study Population}

People with chronic diseases may be included in the representative National Panel of people with Chronic illness or Disability (NPCD) [26]. Inclusion criteria for the NPCD are age 15 or older, diagnosed with a somatic chronic disease, aware of the diagnosis, having a life expectancy of more than 6 months, mentally capable of participating, and not permanently institutionalized. Every year, 500 new panel members are selected to replace panel members who have withdrawn or who have participated for 4 years. The questions on telemonitoring were posed in 2015, 2017, and 2019. 
Nurses are participants in a representative nursing staff panel. The nursing staff panel consists of a nationwide group of nursing staff members (nurses, caregivers, and practice assistants) in various health care settings who deliver direct patient care. The recruitment of members of the nursing staff panel takes place through a random sample of two pension funds. Together, these pension funds register all employees in the Dutch health care sector. Nursing staff were asked to participate in health care research for various purposes. People who agreed and who delivered direct nursing care to patients could join the nursing staff panel. The questions on telemonitoring were asked annually, from 2014 until 2019. For this study, the data of nurses working in primary care, secondary care, and elderly care were used. For 2014 until 2016, the data of nurses working in the curative sectors (practice nurses and nurses working in hospital care) were taken together. From 2017 onwards, these sectors were split into two samples.
General practitioners and medical specialists are participants in a representative doctor's panel. Included are all registered GPs and medical specialists of the Royal Dutch Medical Association. Inclusion criteria for participating in the eHealth-monitor were practicing in the past year and being involved in the diagnosis or treatment of patients. From these doctors, certain specializations were excluded: public and occupational health, forensic medicine, addiction medicine, and psychiatry. The questions on telemonitoring were asked annually, from 2014 until 2019.

\section{Questionnaires}

All participants were asked about their use of telemonitoring and experience with its advantages and disadvantages in the previous 12 months. In addition, HCPs were asked for which portion of patients telemonitoring was used and for which patient groups relevant (Textbox 1). 
Textbox 1. Questionnaires.

Telemonitoring: Remote monitoring of a patient, in which they measure their own health values (for example, blood pressure, blood sugar level) using a meter, sensor, or other device in the home situation and in which they could also respond to some questions. The HCP receives these data digitally.

\section{People with chronic diseases who measure health values themselves}

- Which of the following statements apply to you? (multiple answers possible)

- I electronically submit my self-measured health values to my health care provider (eg, by email or automatically via computer or mobile app) $(2015,2017,2019)$

- $\quad$ My health care provider can see my health data on a website or in a mobile app $(2015,2017,2019)$

- My health care provider looks at my self-measured health data before or during a consultation and discusses it with me (2015, 2017, 2019)

- $\quad$ My health care provider keeps an eye on my self-measured health data remotely and contacts me if anything is wrong (2015, 2017, 2019)

- Can you say how desirable or necessary telemonitoring is for you? (2017)

- $\quad$ Could you please answer the following statements? (2019) I notice or think that telemonitoring...

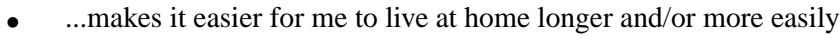

- $\quad$...takes a lot of effort for me

- $\quad$...improves my care

- $\quad$...makes me very tense

Nurses

- Has telemonitoring been used in your organization in the past year? (2014-2019)

- If so, what proportion of your clients/patients use telemonitoring (estimated)? $(2016,2017,2019)$

- If so, what proportion of your clients do you think telemonitoring makes sense for (estimated)? (2019)

- What advantages and disadvantages do you experience with telemonitoring or expect from it? (multiple answers possible) (2019)

\section{General practitioners}

- Could you state whether telemonitoring is applied to the following patient groups (in your practice)? If telemonitoring is not applied, could you please state whether there are plans to start within a year and whether you would like to do so? (2014-2017)

- In your practice, some of your patients with diabetes are currently being monitored by telemonitoring. Could you please estimate the proportion of your diabetes patients for whom you think telemonitoring is sensible? What proportion of your diabetes patients do use it? (2015-2017)

- Is telemonitoring of patients relevant to you or your practice, and is it used within your practice for some or all of the patients? (2019)

- Could you estimate the size of the group of patients for whom you think telemonitoring is sensible and for whom you or other HCPs actually use it in your practice? (2019)

- What advantages and disadvantages do you experience with telemonitoring or expect from it? (multiple answers possible) (2019)

\section{Medical specialists}

- Is telemonitoring of patients relevant to your medical specialty, and is it applied by your department for some or all patients? (2014-2017, 2019)

- $\quad$ For which group of your patients is telemonitoring relevant? (2015-2017)

- Could you estimate the size of the group of patients for whom you think telemonitoring is sensible and for whom you or other HCPs actually use it at your department? (2015-2017, 2019)

- What advantages and disadvantages do you experience with telemonitoring or expect from it? (multiple answers possible) (2019)

\section{Data Analysis}

Descriptive analyses were conducted to study the use and experiences of telemonitoring. Data from the questionnaires among people with a chronic disease and nursing staff were analyzed using Stata, version 15.0 (StataCorp). The results from the questionnaires among GPs and medical specialists were analyzed using SPSS, version 25.0 (IBM Corp).
For questions asked to people with chronic diseases, the descriptive analyses were weighted for age and gender in such a way that it resembled the distribution of age and gender within the Dutch population from age 18 years, based on data from Statistics Netherlands. We applied a weighting factor ranging from 0.65 to 2.28 . The samples for nurses and GPs are fairly representative of the Dutch population of nurses and GPs regarding gender, but the response is not representative for age: GPs younger than 35 years and GPs and nurses 50 years and 
older responded more often. Nevertheless, we did not use a weight factor to correct for this because applying the weight factor did not affect the results. For questions asked to medical specialists, the descriptive analyses were weighted for type of specialty. We applied a weighting factor ranging from 0.5 to 1.7.

\section{Results}

\section{Participants}

Over the years, data were used from 485-633 people with a chronic disease, 322-607 nurses working in elderly care,
220-367 nurses working in the curative disciplines (primary and secondary care), 225-396 GPs, and 184-386 medical specialists who answered questions about telemonitoring (Table $1)$. The mean age of people with chronic disease was 64.5 to 66.4 years. The mean age of nurses varied from 46.7 to 52.2 years. The mean ages of GPs and medical specialists ranged from 50.0 to 52.6 years and 49.4 to 53.9 years, respectively. Approximately half of the people with chronic disease and the doctors were men; among nurses, only $3.5 \%$ (21/607) to $16.1 \%$ $(25 / 155)$ were men. 
Table 1. Study population per year. ${ }^{\text {a }}$

\begin{tabular}{|c|c|c|c|c|c|c|}
\hline Characteristic & 2014 & 2015 & 2016 & 2017 & 2018 & 2019 \\
\hline \multicolumn{7}{|l|}{ People with chronic disease } \\
\hline Responses, $\mathrm{n}$ & $-\mathrm{b}$ & 1448 & - & 1357 & - & 1292 \\
\hline Telemonitoring responses, $\mathrm{n}^{\mathrm{c}}$ & - & 604 & - & 633 & - & 485 \\
\hline Male, $\mathrm{n}(\%)$ & - & $315(52.2)$ & - & $304(48.0)$ & - & $234(48.2)$ \\
\hline Age (years), mean (SD) & - & $64.9(12.7)$ & - & $66.4(12.1)$ & - & $64.5(11.9)$ \\
\hline Low education, $\mathrm{n}(\%)$ & - & $133(22.0)$ & - & $156(24.6)$ & - & 95 (19.6) \\
\hline \multicolumn{7}{|l|}{ Nurses in elderly care } \\
\hline Telemonitoring responses, $\mathrm{n}$ & 408 & 607 & 433 & 341 & 322 & 325 \\
\hline Male, $\mathrm{n}(\%)$ & $18(4.4)$ & $21(3.5)$ & $20(4.6)$ & $15(4.4)$ & $29(9.0)$ & $19(5.8)$ \\
\hline Age (years), mean (SD) & $50.8(8.9)$ & $48.9(10.8)$ & $49.7(10.3)$ & $52.2(9.5)$ & $50.1(10.8)$ & $50.9(11.1)$ \\
\hline \multicolumn{7}{|l|}{ Nurses in curative sectors } \\
\hline Telemonitoring responses, $\mathrm{n}$ & 262 & 316 & 220 & - & - & - \\
\hline Male, n (\%) & $26(9.9)$ & $36(11.4)$ & $25(11.4)$ & - & - & - \\
\hline Age (years), mean (SD) & $48.8(9.6)$ & $46.7(11.4)$ & $48.4(10.7)$ & - & - & - \\
\hline \multicolumn{7}{|l|}{ Practice nurses } \\
\hline Telemonitoring responses, $\mathrm{n}$ & - & - & - & 212 & 124 & 109 \\
\hline Male, $\mathrm{n}(\%)$ & - & - & - & $12(5.7)$ & $8(6.5)$ & $8(7.3)$ \\
\hline Age (years), mean (SD) & - & - & - & $50.8(8.6)$ & $50.4(9.0)$ & $52.0(9.1)$ \\
\hline \multicolumn{7}{|l|}{ Nurses in hospital care } \\
\hline Telemonitoring responses, $\mathrm{n}$ & - & - & - & 155 & 211 & 205 \\
\hline Male, n (\%) & - & - & - & $25(16.1)$ & $29(13.7)$ & $27(13.2)$ \\
\hline Age (years), mean (SD) & - & - & - & $49.4(11.0)$ & $50.0(11.2)$ & $48.2(12.4)$ \\
\hline \multicolumn{7}{|l|}{ General practitioners } \\
\hline Telemonitoring responses, $\mathrm{n}$ & - & 396 & 316 & 290 & - & 225 \\
\hline Male, n (\%) & - & $194(49.0)$ & $162(51.3)$ & $133(45.9)$ & - & $106(47.1)$ \\
\hline Age (years), mean (SD) & - & $50.0(10.2)$ & $51.1(9.9)$ & $51.5(9.7)$ & - & $52.6(9.1)$ \\
\hline \multicolumn{7}{|l|}{ Medical specialists } \\
\hline Telemonitoring responses, $\mathrm{n}^{\mathrm{d}}$ & - & 386 & 274 & 253 & - & 184 \\
\hline Male, n (\%) & - & $203(52.6)$ & $151(55.1)$ & $153(60.5)$ & - & $118(64.1)$ \\
\hline Age (years), mean (SD) & - & $49.8(11.3)$ & $49.4(11.1)$ & $51.9(11.3)$ & - & $53.9(9.7)$ \\
\hline
\end{tabular}

a Among general practitioners and medical specialists, the questions in 2015, 2016, and 2017 were different from those in 2019.

${ }^{\mathrm{b}}$ Not available.

${ }^{\mathrm{c}}$ Question was only asked to persons who measured health outcomes by themselves.

${ }^{\mathrm{d}}$ Weighted by type of specialty.

\section{Actual Use of Telemonitoring}

In $2019,5.8 \%(28 / 485)$ of people with a chronic disease stated that their HCP monitors the health values remotely and contacts them if anything looks wrong (Table 2). In 2015, this figure was $3.3 \%$ (20/604). Most of them had been diagnosed with cardiovascular disease or diabetes. In 2019, 38.0\% (78/205) of nurses working in secondary care and $40.4 \%$ (44/109) in primary care stated that their organization uses telemonitoring. In 2014, this percentage was $34.0 \%$ (89/262) for nurses working in the curative disciplines (both hospital and general practice nurses). Among nurses working in elderly care this was $8.9 \%(29 / 325)$ in 2019 and $11.3 \%(46 / 408)$ in 2014. In addition, $18.2 \%$ (41/225)of GPs and 19.6\% (36/184)of medical specialists stated that telemonitoring was used in their organizations in 2019. These percentages were $17.0 \%$ and $11.2 \%$, respectively, in 2014 . Among medical specialists, this number has grown significantly over the years $\left(\chi_{4}^{2}=12.3, P=.02\right)$. Up to $10 \%$ of the targeted 
patient group, including people with diabetes, is reckoned to be suitable for using telemonitoring.

Table 2. Proportions of patients and health care professionals (HCPs) using telemonitoring, from 2014 to 2019.

\begin{tabular}{|c|c|c|c|c|c|c|}
\hline Population using telemonitoring & 2014 & 2015 & 2016 & 2017 & 2018 & 2019 \\
\hline Patients with a chronic disease, $\mathrm{n}(\%)^{\mathrm{a}}$ & $-b$ & $20(3.3)$ & - & $37(5.8)$ & - & $28(5.8)$ \\
\hline \multicolumn{7}{|l|}{ Elderly care } \\
\hline Nurses, $\mathrm{n}(\%)^{\mathrm{c}}$ & $46(11.3)$ & $70(11.5)$ & - & - & - & $29(8.9)$ \\
\hline Patients using telemonitoring, $\mathrm{n}(\operatorname{mode} \%)^{\mathrm{d}}$ & - & - & $27(1-10)$ & $25(1-10)$ & - & $17(1-10)$ \\
\hline \multicolumn{7}{|l|}{ Primary/secondary care } \\
\hline Nurses, n (\%) & $89(34.0)$ & $126(39.9)$ & $84(38.2)$ & - & - & - \\
\hline Patients using telemonitoring, $\mathrm{n}$ (mode \%) & - & - & $18(1-10)$ & - & - & - \\
\hline \multicolumn{7}{|l|}{ Primary care } \\
\hline Nurses, n (\%) & - & - & - & $85(40.1)$ & $58(46.8)$ & $44(40.4)$ \\
\hline \multicolumn{7}{|l|}{ Secondary care } \\
\hline Nurses, n (\%) & - & - & - & $50(32.3)$ & $80(37.9)$ & $78(38.0)$ \\
\hline Patients using telemonitoring, $\mathrm{n}$ (mode \%) & - & - & - & $14(1-10)$ & - & $22(1-10)$ \\
\hline General practitioners, $n(\%)^{c}$ & $29(17.0)$ & $49(12.4)$ & $41(13.0)$ & $26(9.0)$ & - & $41(18.2)$ \\
\hline Group using telemonitoring, $\mathrm{n}$ (mode group) & 25 (Diabetes) & 43 (Diabetes) & 37 (Diabetes) & 21 (Diabetes) & - & - \\
\hline Relevant for diabetes, $\mathrm{n}(\text { mode } \%)^{\mathrm{d}}$ & - & $26(1-10)$ & $20(1-10)$ & $10(1-10)$ & - & - \\
\hline Medical specialists, $\mathbf{n}(\%)^{\mathrm{c}}$ & $18(11.2)$ & $41(10.6)$ & $26(9.5)$ & $29(11.5)$ & - & $36(19.6)$ \\
\hline Relevant for patients, $\mathrm{n}(\text { mode } \%)^{\mathrm{d}}$ & - & $24(1-10)$ & $19(1-10)$ & - & - & - \\
\hline Relevant for patient group, $\mathrm{n}$ (mode group) ${ }^{\mathrm{e}}$ & - & 13 (Diabetes) & 9 (Diabetes) & 11 (Diabetes) & - & - \\
\hline
\end{tabular}

${ }^{\mathrm{a}}$ The proportion of responding patients stating they are monitored on self-reported health measures by HCP (remotely).

${ }^{b}$ Not available.

${ }^{\mathrm{c}}$ The proportion of responding HCPs stating that telemonitoring is relevant or is used at their department, practice, or organization. Difference between years $\left(\chi_{4}^{2}=12.3 ; P=.02\right)$.

${ }^{\mathrm{d}}$ Proportion of patients using telemonitoring according to the HCPs; possible answers: none, up to $10 \%$, up to $20 \%$, up to $50 \%$, up to $100 \%$, I don't know.

${ }^{\mathrm{e}}$ The most often mentioned were these groups: diabetes, heart failure, chronic obstructive pulmonary disease, and asthma.

\section{Advantages and Disadvantages of Telemonitoring}

Of patients with a chronic disease, $40.4 \%$ (421/1043) agreed or totally agreed with the statement "telemonitoring improves my comfort" (353/1043, 33.8\% answered “don't know”). In addition, $31.9 \%(334 / 1047)$ agreed or totally agreed with "telemonitoring lets me stay at home longer and/or live more comfortably" (405/1050, 38.7\% answered "don't know") (Table 3).

On the other hand, $7.7 \%$ agreed or totally agreed with "telemonitoring takes me a lot of effort" (36.4\% answered "don't know"). Among HCPs, the most widely experienced or expected advantage of telemonitoring mentioned was "telemonitoring improves patients' self-management" $(57 / 71,80.3 \%$ of nurses working in primary care; $71 / 124,57.3 \%$ of nurses working in secondary care; $84 / 134,62.7 \%$ of nurses working in elderly care; $135 / 225,60 \%$ of GPs; 63/176, 35.8\% of medical specialists) (Table 4). In addition, 59.2\% (42/71) of nurses working in primary care and $46.8 \%(58 / 124)$ of nurses working in secondary care stated that their experience or expectation of telemonitoring was that they would get a better understanding of the health condition of the patient. Of nurses working in elderly care, $39.6 \%$ (53/134) experienced or expected telemonitoring to reduce the workload. Moreover, $42.2 \%$ $(95 / 225)$ of GPs said that telemonitoring let them tailor the care plan to the situation of their patients better. Of medical specialists, $34.7 \%(61 / 176)$ expected or had observed that telemonitoring gave them spare time for patients and caregivers/relatives. 
Table 3. Opinions of telemonitoring from patients with chronic diseases ( $\mathrm{n}=1023-1050), 2019$.

\begin{tabular}{|c|c|c|c|c|c|c|}
\hline \multirow[t]{2}{*}{ I notice or think that telemonitoring: } & \multicolumn{6}{|c|}{ Agreement with statement, $\mathrm{n}(\%)$} \\
\hline & Totally disagree & Disagree & $\begin{array}{l}\text { Neither agree } \\
\text { nor disagree }\end{array}$ & Agree & $\begin{array}{l}\text { Totally } \\
\text { agree }\end{array}$ & I don’t know \\
\hline Lets me live at home longer and/or more easily $(\mathrm{n}=1047)$ & $47(4.5)$ & $62(5.9)$ & $199(19.0)$ & $235(22.4)$ & $99(9.5)$ & $405(38.7)$ \\
\hline Improves my comfort $(\mathrm{n}=1043)$ & $42(4.0)$ & $50(4.8)$ & $177(17.0)$ & $331(31.7)$ & $90(8.6)$ & $353(33.8)$ \\
\hline Takes me a lot of effort ( $\mathrm{n}=1023)$ & $83(8.1)$ & $249(24.3)$ & $246(24.0)$ & $61(6.0)$ & $12(1.2)$ & $372(36.4)$ \\
\hline Improves my care $(\mathrm{n}=1035)$ & $41(4.0)$ & $66(6.4)$ & $234(22.6)$ & $241(23.3)$ & $82(7.9)$ & $371(35.8)$ \\
\hline Makes me very tense $(n=1027)$ & $104(10.1)$ & $220(21.4)$ & $238(23.2)$ & $77(7.5)$ & $17(1.7)$ & $371(36.1)$ \\
\hline
\end{tabular}

Table 4. Experienced or expected advantages and disadvantages of telemonitoring assessed by health care providers, 2019.

\begin{tabular}{|c|c|c|c|c|c|}
\hline Characteristic & $\begin{array}{l}\text { Nurses, primary } \\
\text { care }\end{array}$ & $\begin{array}{l}\text { Nurses, sec- } \\
\text { ondary care }\end{array}$ & $\begin{array}{l}\text { Nurses, elderly } \\
\text { care }\end{array}$ & $\begin{array}{l}\text { General practi- } \\
\text { tioners }\end{array}$ & $\begin{array}{l}\text { Medical spe- } \\
\text { cialists }\end{array}$ \\
\hline Advantages respondents, $\mathrm{n}$ & 71 & 124 & 134 & 225 & 176 \\
\hline \multicolumn{6}{|l|}{ Advantages, $\mathbf{n}(\%)^{\mathrm{a}}$} \\
\hline It reduces the workload & $10(14.1)$ & $23(18.5)$ & $53(39.6)$ & $16(7.1)$ & $14(8.0)$ \\
\hline It reduces the workload of my assistants & $-\mathrm{b}$ & - & - & $56(24.9)$ & $18(10.2)$ \\
\hline It saves time for patients and or caregivers/relatives & $32(45.1)$ & $58(46.8)$ & $45(33.6)$ & $86(38.2)$ & $61(34.7)$ \\
\hline It improves the quality of care in my organization & $34(47.9)$ & $50(40.3)$ & $38(28.4)$ & $77(34.2)$ & $44(25.0)$ \\
\hline It improves the self-management of the patient & $57(80.3)$ & $71(57.3)$ & $84(62.7)$ & $135(60.0)$ & $63(35.8)$ \\
\hline $\begin{array}{l}\text { I have a better understanding of my clients' health } \\
\text { condition }\end{array}$ & $42(59.2)$ & $58(46.8)$ & $43(32.1)$ & $77(34.2)$ & $47(26.7)$ \\
\hline $\begin{array}{l}\text { It lets me tailor the care plan better to my patients, } \\
\text { situation }\end{array}$ & $38(53.5)$ & $47(37.9)$ & $32(23.9)$ & $95(42.2)$ & $45(25.6)$ \\
\hline It lets patients ask for help in time & $20(28.2)$ & $52(41.9)$ & $38(28.4)$ & $67(29.8)$ & $32(18.2)$ \\
\hline Other advantages & - & $7(5.6)$ & $3(2.2)$ & $9(4.0)$ & $5(2.8)$ \\
\hline I do not expect or experience any advantages & - & $9(7.3)$ & $23(17.2)$ & $32(14.2)$ & $48(27.3)$ \\
\hline Disadvantages respondents, $\mathrm{n}$ & 68 & 113 & 130 & 225 & 181 \\
\hline \multicolumn{6}{|l|}{ Disadvantages, $\mathbf{n}(\%)^{\mathrm{a}}$} \\
\hline It takes me a lot of time to monitor/check health values & $32(47.1)$ & $21(18.6)$ & $13(10.0)$ & $108(48.0)$ & $56(30.9)$ \\
\hline It takes me a lot of time to follow up notifications & $29(42.6)$ & $19(16.8)$ & $15(11.5)$ & $117(52.0)$ & $51(28.2)$ \\
\hline It takes a lot of time for my assistants & - & - & - & $99(44.0)$ & $45(24.9)$ \\
\hline $\begin{array}{l}\text { It ensures that patients and/or relatives contact me } \\
\text { more often }\end{array}$ & $20(29.4)$ & $22(19.5)$ & $21(16.2)$ & $83(36.9)$ & $40(22.1)$ \\
\hline It worries patients and/or relatives & $10(14.7)$ & $20(17.7)$ & $23(17.7)$ & $81(36.0)$ & $33(18.2)$ \\
\hline I find it difficult to work with it & - & - & - & $16(7.1)$ & $7(3.9)$ \\
\hline The system provides unreliable data & - & - & - & $52(23.1)$ & $33(18.2)$ \\
\hline The application is not secure & - & - & - & $20(8.9)$ & $7(3.9)$ \\
\hline $\begin{array}{l}\text { I find it difficult to estimate which patients can work } \\
\text { with it }\end{array}$ & $15(22.1)$ & $22(19.5)$ & $37(28.5)$ & $94(41.8)$ & $52(28.7)$ \\
\hline Other disadvantages & $8(11.8)$ & $7(6.2)$ & $8(6.2)$ & $18(8.0)$ & $20(11.0)$ \\
\hline I do not expect or experience any disadvantages & $13(19.1)$ & $49(43.4)$ & $56(43.1)$ & $13(5.8)$ & $33(18.2)$ \\
\hline
\end{tabular}

${ }^{\mathrm{a}}$ Multiple answers possible.

${ }^{\mathrm{b}}$ Not available.

A total of $43.4 \%(49 / 113)$ of nurses working in secondary care and $43.1 \%(56 / 130)$ of nurses working in elderly care did not https://www.jmir.org/2021/5/e24908 expect or experience any disadvantages of telemonitoring. In contrast, $47.1 \%(32 / 68)$ of nurses working in primary care 
expected or noted that telemonitoring takes a lot of time to monitor and check health values. Of GPs and medical specialists, $48.0 \%(108 / 225)$ and $30.9 \%$ (56/181), respectively, expected or experienced this. In addition, 42.6\% (29/68) of nurses working in primary care, $52.0 \%$ (117/225) of GPs, and $28.2 \%$ (51/181) of medical specialists expected or experienced that using telemonitoring would take up a lot of time following up on alerts. Moreover, $19.5 \%$ (22/113) of nurses working in secondary care, $28.5 \%(37 / 130)$ of the nurses working in elderly care, and $28.7 \%(52 / 181)$ of medical specialists expected or experienced difficulties in estimating which patients could handle telemonitoring.

\section{Discussion}

\section{Principal Findings}

Our study adds new insights to current scientific studies of telemonitoring, as it investigated the actual nationwide uptake of telemonitoring for all patient groups in chronic care over a long period of time (before the COVID-19 pandemic). Findings from the perspectives of nurses, GPs, medical specialists, and patients with chronic diseases can assist the implementation of telemonitoring and the uptake of telemonitoring in daily practice. The current COVID-19 pandemic has called for rapid implementation of telemonitoring for acute and subacute diseases in 2020. Future editions of the Dutch eHealth-monitor might present the impact of COVID-19 on a rising uptake of telemonitoring [27] and on new opinions and experiences with telemonitoring. Strengths of our study include the large sample size, the external validity and reliability of the data, and the representativeness of the various groups of participants (people with chronic diseases, nurses, GPs, and medical specialists). Nevertheless, there are also some limitations. Due to the specific factors in the Netherlands that boosted the implementation of telemonitoring, our study results can only partly be extrapolated to other countries. In addition, the use of telemonitoring was only investigated by asking potential users in health care; we did not investigate data from other resources such as health care insurers or telehealth companies. As well, our quantitative approach is best suited to answering "what," "when," and "who" questions and less well-suited to "how" and "why" questions. The opinions and experiences with telemonitoring that we investigated therefore do not fully explain the factors concerning the implementation and uptake of telemonitoring. Even so, our results concerning the experiences of HCPs are underlined by qualitative studies [28-30]. Other benefits and barriers found are "an increased feeling of safety" and "insufficient familiarity with the technology" [28-30]. In addition, HCPs need to add telemonitoring to the health care process, with a precise description of the target group, task allocation for data monitoring, and support for patients from within the team [31,32].

\section{Conclusion}

The uptake of telemonitoring in Dutch chronic care remained stable during 2014-2019 but increased among medical specialists. According to both patients and professionals, telemonitoring improves the quality of life and quality of care. Skills for appropriately including eligible patients and allocating the tasks of data monitoring and follow-up care within the team would help to further increase the use of telemonitoring.

\section{Acknowledgments}

The project was funded by the Dutch Ministry of Health, Welfare and Sport. The Dutch Ministry of Health, Welfare and Sport had no role in the collection, analysis, or interpretation of data or in writing the manuscript. The authors would like to acknowledge all other people who were involved in data collection during 2013-2019; in particular, Johan Krijgsman, Ilse Swinkels, Judith de Jong, Janke de Groot, Anne Brabers, Lies van Gennip, Karlijn de Bruin, and Annemarie Lamain. In addition, the authors would like to thank the members of the advisory committee in 2019: Guus Schrijvers, Christine Aberson-Blok, Arina Burghouts, Jeroen Crasborn, Henny Mulders, Henk Herman Nap, Sjaak Nouwt, Renée Verwey, Karin Zwager-Ankone, and Nienke Zwennes.

\section{Authors' Contributions}

MWJH and HRVP were the main contributors in data analysis and in writing the manuscript. MW, MWJH, BvL, CK, and RDF were involved in developing the questionnaires. All authors were involved in the process of data management. MWJH, HRVP, MMM, MW, and BvL were involved in the data analysis. All authors read and approved the final manuscript.

\section{Conflicts of Interest}

None declared.

\section{References}

1. Oh H, Rizo C, Enkin M, Jadad A. What is eHealth (3): a systematic review of published definitions. J Med Internet Res 2005 Feb 24;7(1):e1 [FREE Full text] [doi: 10.2196/jmir.7.1.e1] [Medline: 15829471]

2. Epstein RM, Fiscella K, Lesser CS, Stange KC. Why the nation needs a policy push on patient-centered health care. Health Aff (Millwood) 2010 Aug;29(8):1489-1495. [doi: 10.1377/hlthaff.2009.0888] [Medline: 20679652]

3. European Commission, Liikanen E. The Importance of eHealth in Europe. 2003. URL: https://ec.europa.eu/commission/ presscorner/detail/en/SPEECH $03 \quad 608$ [accessed 2020-01-03]

4. World Health Organization. From innovation to implementation: eHealth in the WHO European Region. 2016. URL: https:/ /www.euro.who.int/ data/assets/pdf file/0012/302331/From-Innovation-to-Implementation-eHealth-Report-EU.pdf [accessed 2020-01-07] 
5. Telehealth programs. 2018. URL: https://www.hrsa.gov/rural-health/telehealth/index.html [accessed 2019-11-01]

6. Larsen SB, Sørensen NS, Petersen MG, Kjeldsen GF. Towards a shared service centre for telemedicine: Telemedicine in Denmark, and a possible way forward. Health Informatics J 2016 Dec;22(4):815-827 [FREE Full text] [doi: 10.1177/1460458215592042] [Medline: 26261216]

7. Anker SD, Koehler F, Abraham WT. Telemedicine and remote management of patients with heart failure. Lancet 2011 Aug 20;378(9792):731-739. [doi: 10.1016/S0140-6736(11)61229-4] [Medline: 21856487]

8. Lopez-Villegas A, Catalan-Matamoros D, Robles-Musso E, Bautista-Mesa R, Peiro S. Cost-utility analysis on telemonitoring of users with pacemakers: The PONIENTE study. J Telemed Telecare 2019 May;25(4):204-212. [doi: 10.1177/1357633X18767184] [Medline: 29621908]

9. Boyne JJ, Vrijhoef HJ, Spreeuwenberg M, De Weerd G, Kragten J, Gorgels AP, TEHAF investigators. Effects of tailored telemonitoring on heart failure patients' knowledge, self-care, self-efficacy and adherence: a randomized controlled trial. Eur J Cardiovasc Nurs 2014 Jun;13(3):243-252. [doi: 10.1177/1474515113487464] [Medline: 23630403]

10. Sul A, Lyu D, Park D. Effectiveness of telemonitoring versus usual care for chronic obstructive pulmonary disease: A systematic review and meta-analysis. J Telemed Telecare 2020 May;26(4):189-199. [doi: 10.1177/1357633X18811757] [Medline: $\underline{30541375]}$

11. Qian W, Lam TT, Lam HHW, Li C, Cheung YT. Telehealth Interventions for Improving Self-Management in Patients With Hemophilia: Scoping Review of Clinical Studies. J Med Internet Res 2019 Jul 10;21(7):e12340 [FREE Full text] [doi: 10.2196/12340] [Medline: 31293241]

12. Kvedar J, Coye MJ, Everett W. Connected health: a review of technologies and strategies to improve patient care with telemedicine and telehealth. Health Aff (Millwood) 2014 Feb;33(2):194-199. [doi: 10.1377/hlthaff.2013.0992] [Medline: 24493760]

13. Hamine S, Gerth-Guyette E, Faulx D, Green BB, Ginsburg AS. Impact of mHealth chronic disease management on treatment adherence and patient outcomes: a systematic review. J Med Internet Res 2015 Feb 24;17(2):e52 [FREE Full text] [doi: 10.2196/jmir.3951] [Medline: 25803266]

14. Nissen L, Lindhardt T. A qualitative study of COPD-patients' experience of a telemedicine intervention. Int J Med Inform 2017 Nov;107:11-17. [doi: 10.1016/j.ijmedinf.2017.08.004] [Medline: 29029687]

15. Mathavakkannan S, Bowser M, Doyle S, Hoare A, Rehsi G. Promoting patient empowerment and sustainability in kidney care using telemedicine. Int J Integr Care 2014 Nov 01;14(8):2. [doi: 10.5334/ijic.1816]

16. van der Burg JM, Aziz NA, Kaptein MC, Breteler MJ, Janssen JH, van Vliet L, et al. Long-term effects of telemonitoring on healthcare usage in patients with heart failure or COPD. Clinical eHealth 2020;3:40-48. [doi: 10.1016/j.ceh.2020.05.001]

17. Ziefle M, Klack L, Wilkowska W, Holzinger A. Acceptance of telemedical treatments - A medical professional point of view. 2013 Presented at: International conference on human interface and the management of information; 2013; Berlin, Germany p. 21-26. [doi: 10.1007/978-3-642-39215-3 39]

18. Barello S, Triberti S, Graffigna G, Libreri C, Serino S, Hibbard J, et al. eHealth for Patient Engagement: A Systematic Review. Front Psychol 2015;6:2013 [FREE Full text] [doi: 10.3389/fpsyg.2015.02013] [Medline: 26779108]

19. Ross J, Stevenson F, Lau R, Murray E. Factors that influence the implementation of e-health: a systematic review of systematic reviews (an update). Implement Sci 2016 Oct 26;11(1):146 [FREE Full text] [doi: 10.1186/s13012-016-0510-7] [Medline: 27782832]

20. Eurostat. Digital economy and society statistics - households and individuals. URL: https://ec.europa.eu/eurostat/ statistics-explained/index.php/Digital_economy_and_society_statistics_-_households_and_individuals [accessed 2020-01-07]

21. Statistics Netherlands (CBS), Eurostat. ICT use by households and individuals. URL: https://opendata.cbs.nl/statline/\#/ CBS/en/?fromstatweb [accessed 2019-11-01]

22. National Institute for Public Health and Environment (RIVM), Ossebaard HC, de Bruijn ACP, van Gemert-Pijnen JEWC, Geertsma RE. Risk related to the use of ehealth technologies; an explorative study. 2012. URL: https://www.rivm.nl/ bibliotheek/rapporten/360127001.pdf [accessed 2020-01-07]

23. Inspectorate on health and youth care (IGJ). Toetsingskader IGJ; inzet van e-health door zorgaanbieders. Report. 2018. URL: https://www.igj.nl/binaries/igj/documenten/toetsingskaders/2019/10/18/ toetsingskader-inzet-van-e-health-door-zorgaanbieders/Toetsingskader IGJ Inzet+e-health+door+zorgaanbieders.pdf [accessed 2020-01-07]

24. Nivel, Kroneman M, Boerma W, van den Berg M, Groenewegen P, de Jong J, et al. Health systems in transition. 2016. URL: https://www.euro.who.int/ data/assets/pdf file/0016/314404/HIT Netherlands.pdf [accessed 2020-01-07]

25. NIVEL, Meurs M, Huygens M, Keuper J, de Groot J, Friele R. Slimme zorg thuis bij COPD en hartfalen Ervaringen en ambities van vijf voorloper initiatieven In Dutch. 2019. URL: https://nivel.nl/sites/default/files/bestanden/1003591.pdf [accessed 2020-01-07]

26. Rijken M, Bensing J. The National Panel of Patients with Chronic Diseases: An infrastructure for patient-centered research. TSG Tijdschrift Voor Gezondheidswetenschappen 2000;78:5.

27. Lai SHS, Tang CQY. Telemedicine and COVID-19: beyond just virtual consultations - the Singapore experience. Bone Jt Open 2020 Jun;1(6):203-204 [FREE Full text] [doi: 10.1302/2633-1462.16.BJO-2020-0042.R1] [Medline: 33225290] 
28. Van der Zweth J, Askari M, Brinkhuis M, van Lettow B. The Added Value of Telehomecare for Heart Patients, Healthcare Professionals, and Healthcare Organizations. 2017. URL: https://dspace.library.uu.nl/bitstream/handle/1874/354694/ van\%20der\%20Zweth\%20-\%205675383\%20-\%20Thesis.pdf [accessed 2020-01-07]

29. Morton K, Dennison L, May C, Murray E, Little P, McManus RJ, et al. Using digital interventions for self-management of chronic physical health conditions: A meta-ethnography review of published studies. Patient Educ Couns 2017 Apr;100(4):616-635 [FREE Full text] [doi: 10.1016/j.pec.2016.10.019] [Medline: 28029572]

30. Slevin P, Kessie T, Cullen J, Butler MW, Donnelly SC, Caulfield B. A qualitative study of chronic obstructive pulmonary disease patient perceptions of the barriers and facilitators to adopting digital health technology. Digit Health 2019;5:2055207619871729 [FREE Full text] [doi: 10.1177/2055207619871729] [Medline: 31489206]

31. Hallensleben C, van Luenen S, Rolink E, Ossebaard HC, Chavannes NH. eHealth for people with COPD in the Netherlands: a scoping review. Int J Chron Obstruct Pulmon Dis 2019;14:1681-1690 [FREE Full text] [doi: 10.2147/COPD.S207187] [Medline: $\underline{31440044]}$

32. Parker S, Prince A, Thomas L, Song H, Milosevic D, Harris MF, IMPACT Study Group. Electronic, mobile and telehealth tools for vulnerable patients with chronic disease: a systematic review and realist synthesis. BMJ Open 2018 Aug 29;8(8):e019192 [FREE Full text] [doi: 10.1136/bmjopen-2017-019192] [Medline: 30158214]

\section{Abbreviations \\ GP: general practitioner \\ HCP: health care professional \\ NPCD: National Panel of people with Chronic illness or Disability}

Edited by $R$ Kukafka; submitted 09.10.20; peer-reviewed by K Fitzner, O Blanson Henkemans; comments to author 23.11.20; revised
version received 27.11.20; accepted 21.03.21; published 03.05.21
Please cite as:
Huygens $M W J$, Voogdt-Pruis HR, Wouters M, Meurs MM, van Lettow B, Kleijweg C, Friele RD
The Uptake and Use of Telemonitoring in Chronic Care Between 2014 and 2019: Nationwide Survey Among Patients and Health
Care Professionals in the Netherlands
J Med Internet Res 2021;23(5):e24908
URL: $\underline{\text { https://www.jmir.org/2021/5/e24908 }}$
doi: $\underline{10.2196 / 24908}$
PMID: $\underline{33938808}$

CMartine W J Huygens, Helene R Voogdt-Pruis, Myrah Wouters, Maaike M Meurs, Britt van Lettow, Conchita Kleijweg, Roland D Friele. Originally published in the Journal of Medical Internet Research (https://www.jmir.org), 03.05.2021. This is an open-access article distributed under the terms of the Creative Commons Attribution License (https://creativecommons.org/licenses/by/4.0/), which permits unrestricted use, distribution, and reproduction in any medium, provided the original work, first published in the Journal of Medical Internet Research, is properly cited. The complete bibliographic information, a link to the original publication on https://www.jmir.org/, as well as this copyright and license information must be included. 